Article

\title{
Recent Advancement of Sustainable and Renewable Energy in Osmotic Power Generation
}

\author{
Guo-Yong Yew ${ }^{1,2, a}$, Zhen-Shen Liew ${ }^{1,2, b}$, Soon-Onn Lai ${ }^{3, c}$, Thiam-Leng Chew ${ }^{4,5, d}$, \\ Hee-Min Teh ${ }^{1,2, e}$, Siti Habibah Shafiai ${ }^{1,6, \mathrm{f}}$, Man-Kee Lam $^{4,6, \mathrm{~g}}$, Jun-Wei Lim ${ }^{6,7, \mathrm{~h}}$, \\ Pau-Loke Show ${ }^{8, \mathrm{i}}$, and Yeek-Chia $\mathrm{Ho}^{1,2, \mathrm{j}, *}$ \\ 1 Civil and Environmental Engineering Department, Universiti Teknologi PETRONAS, 32610 Seri \\ Iskandar, Perak Darul Ridzuan, Malaysia \\ 2 Centre of Urban Resource Sustainability, Institute of Self-Sustainable Building, Universiti Teknologi \\ PETRONAS, Seri Iskandar, Perak Darul Ridzuan, Malaysia \\ 3 Lee Kong Chian Faculty of Engineering and Science, Universiti Tunku Abdul Rahman, Jalan Sungai Long, \\ Bandar Sungai Long, 43300 Kajang, Malaysia \\ 4 Department of Chemical Engineering, Faculty of Engineering, Universiti Teknologi PETRONAS, 32610 \\ Seri Iskandar, Perak, Malaysia \\ $5 \mathrm{CO}_{2}$ Research Centre (CO2RES), Institute of Contaminant Management, Universiti Teknologi \\ PETRONAS, 32610 Seri Iskandar, Perak, Malaysia \\ 6 Centre for Biofuel and Biochemical Research (CBBR), Institute of Self-Sustainable Building, Universiti \\ Teknologi PETRONAS, 32610 Seri Iskandar, Perak Darul Ridzuan, Malaysia \\ 7 Fundamental and Applied Sciences Department, Universiti Teknologi PETRONAS, Seri Iskandar, Perak \\ Darul Ridzuan 32610, Malaysia \\ 8 Department of Chemical and Environmental Engineering, Faculty of Science and Engineering, University \\ of Nottingham Malaysia, Jalan Broga, 43500 Semenyih, Selangor Darul Ehsan, Malaysia \\ E-mail: ayewguoyong@gmail.com, balfredliew1997@gmail.com, claiso@utar.edu.my, \\ dthiamleng.chew@utp.edu.my, eheemin.teh@utp.edu.my, fsitihabibah.shafiai@utp.edu.my, \\ gjunwei.lim@utp.edu.my, hjunwei.lim@utp.edu.my, ishowpauloke@gmail.com, i,'yeekchia.ho@utp.edu.my \\ (Corresponding author)
}

\begin{abstract}
Investment in clean energy is demand in this century due to abundance of CO2 accumulation in the world to cause several environmental issues. Therefore, harvesting clean energy may assist in reducing carbon footprint in the world to create a green environment for sustainable living. The salinity gradient energy is one of the clean energies with the concept of mixing both salt concentration water from the ocean and fresh water from the river to create an osmotic pressure to power-up the generator for the production of electrical energy. Salinity different between the oceanic salt water and fresh water could produce an equilibrium osmotic pressure that achieve up to 27 bars equivalent from resulting pressure under the water for 200 to 300 meters. The potential of the power production through osmosis power generator is capture at the value of 2000 TWh per year, where in 2018 the world energy consumption was growing $2.3 \%$, in which twice the number compare to the average rate of the growth. The major energy consumption is contributed from fossil fuel and consequently resulted from emissions of $\mathrm{CO} 2$ increased to $33.1 \mathrm{Gt}$ to the atmosphere. This work explained the advantage of using salinity gradient energy and the fundamental principle of blue energy from pressure-retarded osmosis (PRO). Thus, the osmotic power by using different salinity gradient to create energy is widely known as blue energy, in which it is green and sustainable to produce electricity to the local communities.
\end{abstract}

Keywords: Clean energy, osmotic, antifouling membrane, pressure retard osmosis.

ENGINEERING JOURNAL Volume 25 Issue 2

Received 7 February 2020

Accepted 25 November 2020

Published 28 February 2021

Online at https://engj.org/

DOI:10.4186/ej.2021.25.2.193

This article is based on the presentation at the International Conference on Engineering and Industrial Technology (ICEIT 2020) in Chonburi, Thailand,

11th-13th September 2020. 


\section{Introduction}

As the world approaching toward depletion of fossil fuels, alternative energy sources for replacement with clean energy to reduce carbon footprint are needed. Moreover, the constant changes in the global climate caused by the emission of carbon dioxide $\left(\mathrm{CO}_{2}\right)$ which is causing greenhouse gases, it appears to be vital to seek for renewable energy sources to create a green environment for sustainable living. The current environmental issue has urged the innovation of renewable energy sources to reduce environmental pollution and avoid usage of carbon-based fuel in global as primary energy source [1]. In 2018, the world energy consumption was growing $2.3 \%$ in which the number is in 2-fold compared to the average growth rate and consequently resulted from emission of $\mathrm{CO}_{2}$ increased to $33.1 \mathrm{Gt}$ to the atmosphere due to the main power supplied is from carbon-based materials. Harvesting clean and renewable energy sources from the environment to meet the ever-growing energy challenge is crucial to ensure the survival and sustainable development of human civilization. The renewable energy derived from wind, geothermal, solar have attracted great attention in harvesting renewable energy sources recently in meeting the future energy demand.

Salinity gradient or known as blue energy is a type of renewable energy source and without release any toxic gases from the system to the atmosphere. In 1973, salinity gradient energy has been introduced by Prof. Sidney Loeb during observing the Jordan river water meet with the dead sea and given credibility as blue energy source. The fundamental salinity-gradient energy concept of generating power is based on potential energy source and potential different upon mixing both different concentrations of salt from the ocean and river water between the rivers and oceans to produce energy [2]. The process of mobilizing the salinity gradient power generation method often be explained in terms of osmotic power. By utilizing the osmotic pressure, several different techniques have been tried and the most established to generate energy is from the pressure retarded osmosis (PRO). The pressure retarded osmosis method is a viable and current have a prototype plant technology to produce osmotic power from blending two different salinity concentration solvent [3].

\subsection{Principle of Osmosis}

Osmosis pressure generated when a membrane separated by two solutions different salinity solution from a less to high concentration solution until achieving an equalize concentration on both sides of the membrane. For example, given two solutions which are different salinity gradient solutions from two different salinity solutions which are separated by a semipermeable membrane. The system for pressure retarded system PRO should be flow from high salt concentration to low salt concentration solution. The process will continue with the water flux across the semi-permeable membrane until the pressurised on the drawn side reach an optimum condition. However, under no water across the membrane, this also means that the pressure is equivalent to the osmotic pressure of the system. According to Dinger et al. [4], during the combined of high and low salinity solution, the overall of the entropy will increase due to large ions neutralized effect from the salt solution with fresh water solution. According to Dinger et al. [4], for the of salt water from the ocean, an energy of approximately $2.88 \mathrm{MJ}$ per $1 \mathrm{~m} 3$ of fresh water from the river has been mixed with a oceanic salt water solution which can be used to generate electric power by osmotic power generation plant.

In general, osmotic power is derived from the osmosis working mechanism which consists transportation of water molecules through a semi permeate membrane. In between, both side of the membrane created a high chemical concentration different or chemical potential. This may refer to the feed solution with low osmotic pressure and lower level of salinity from fresh water toward high salinity solution through the semipermeable membrane which consists of higher salt concentration and high osmotic pressure when water remains to the side of the drawn solution. As water flux is always opposing the direction of osmotic pressure, where higher osmotic pressure causes more water molecules to flow toward that side because followed the osmosis mechanism water molecules will be attracted by the high concentration ions side. The membrane rejects solute molecules and ions while allowing the passing of feed solution. Osmotic pressure on the other hand when it is applied to the draw solution, causes the flowing of feed solution to halt across the semipermeable membrane. The Van't Hoff equation can be calculated the osmotic pressure $(\pi)$ of any solution shown as below [5].

$$
\pi=i c R T
$$

Equation (1) is representing the osmotic pressure, given $\Delta \pi$ is the osmotic pressure, $\mathrm{i}$ is the osmotic active particles, where the molar concentration $\mathrm{c}\left(\mathrm{mol} \mathrm{L}^{-1}\right), \mathrm{R}$ is the gas constant (8.3144 $\mathrm{Nm} \mathrm{Mol}^{-1} \mathrm{~K}^{-1}$ ), where absolute temperature representing in term of $\mathrm{T}$ in Kelvin as unit.

\subsection{Osmotic Processes and Concepts}

There are four types of feed and drawn solution operating conditions and also the possible osmotic processes from salt and fresh water through a semipermeable membrane. The pressure from the feed toward drawn side is known as forward osmosis FO with the differential $(\Delta \pi)$ which indicate the osmotic pressure different Fig. 1(a) and Fig. 1(b) as the single direction of the water flux from feed to the drawn side through the semi-permeable membrane (J). In FO, $\Delta \pi$, should be 
non-zero $\Delta \pi>0$, and the solutions are at the same magnitude for the input pressure from the saline water as $\Delta \mathrm{P}=0$. Based on Eq. (1), it is denoting the osmotic pressure different for the concentration of the feed and drawn solution. As an example, given the river water with low salinity $\pi \approx 0$ where the drawn solution is high salinity solution normally the salt concentration will be around $\approx 4.5 \%$ and $\pi \approx 39$ bar, which mean the osmotic different will be 39 bar, where corresponding to a hydrostatic pressure which equivalent to a $397.5-\mathrm{m}$ high water column. The water across from low salt density to higher salt density in Fig. 1, entirely operate by the osmotic pressure of the two-differential concentration of the solution. a.

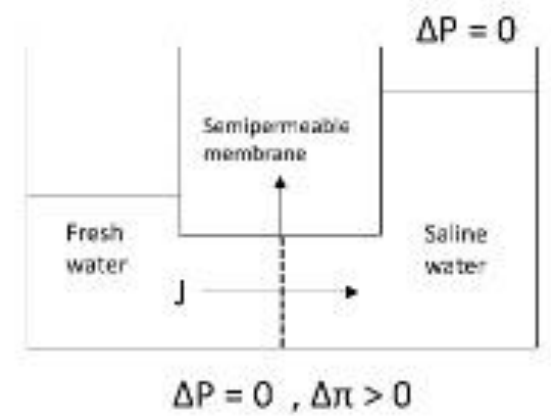

c.

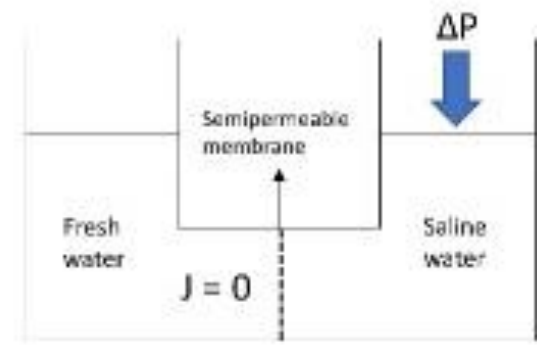

$\Delta \mathrm{P}=\Delta \pi$ b.

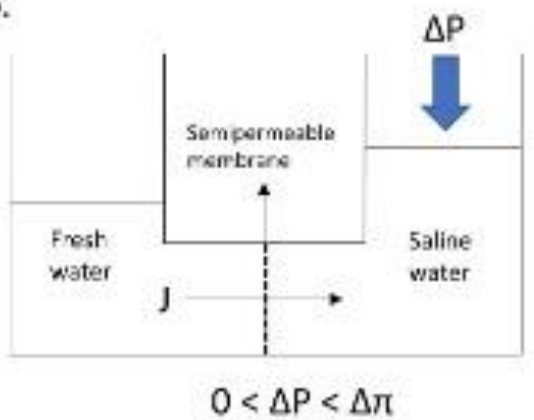

d.

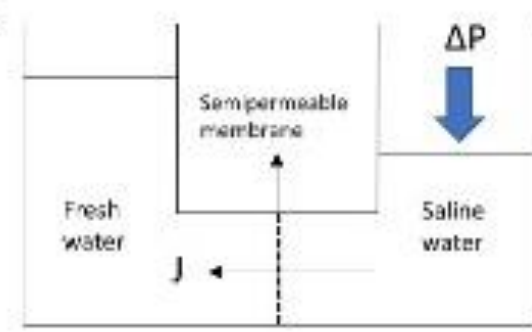

$\Delta P>\Delta \pi$

Fig. 1. Schematic diagram for 4 types of sequential osmotic processes.

The osmotic flow (J) will end upon the water from 'feed solution' side flow toward 'drawn solution' direction across the membrane causing by the increased of high salinity side of hydrostatic pressure. To be more accurate, upon a pressure built up to a $397.5-\mathrm{m}$ will be appear at the high salinity drawn chamber. According to the mathematic equation (2) the flux stops when $\Delta \mathrm{P}$ is equivalent to $\Delta \pi$ and it would cause $\mathrm{J}=0$ as well. In which it has determined osmotic equilibrium as illustrated in Fig. 1(c).

According to Helfer et al. [5], at any step whereby the $\Delta \mathrm{P}$ hydrostatic pressure in between 0 and $\Delta \pi$ osmotic pressure. However, the flux $\mathrm{J}$ reduces the flow rate due to raise the $\Delta \mathrm{P}$ from the water level accumulate from the osmotic process in the water level at the high salinity concentration side. This condition is referred as Pressure Retarded Osmosis (PRO) and is shown in Fig. 1(b). For $\mathrm{PRO}$ is driven by the osmotic pressure from river to sea water to remain the hydrostatic pressure difference $(\Delta \mathrm{P})$ lesser than the osmotic pressure. The mechanism of the osmotic power is particularly followed on this principle. A constant output from the osmotic power supply, the high salinity solution requires a steady osmotic pressure and concentration to increase the volume flow of the high salinity side while the fresh water as feed to have a constant permeate rate across the semi-permeable membrane.

In addition, the fourth osmotic occurrence happened when $\Delta \mathrm{P}>\Delta \pi$, as shown in Fig. 1(d). The operating pressure can be attained if the pressure is applied to the high salinity side which will be exceeded the osmotic pressure. A negative flux is generated when the water flux in the direction from high salinity to low salinity side. This flow pattern from the system is known as Reverse Osmosis (RO) as the solution will have an opposite flux from drawn solution which is the high salinity concentration side toward low salinity direction. Most of the modern seawater desalination plants operate using this principle in which seawater is pressurized in the drawn side in high magnitude to overcome the membrane permeate limit and osmotic pressure to obtain the low salt concentration solution repeated the solution will enhance the water purity. The membrane filtered high salinity solution and only freshwater permeates the output water from $\mathrm{RO}$ process which is consumable upon drinking water quality standard. 


$$
\mathrm{J}=\mathrm{A}(\Delta \pi-\Delta \mathrm{P})
$$

Equation as in (2) denoting that the potential different of the flux through the membrane between two different salinity of the solutions known as $\Delta \pi$, osmotic pressure in term of (bar), the hydrostatic pressure is defined as $\Delta \mathrm{P}$, in bar and membrane types relate to water permeability coefficient A, typically in $L \mathrm{~m}^{-2} h^{-1} \mathrm{bar}^{-1}$.

The processes of four different osmotic condition are justified in Fig. 2. The direction of water flux and pressure exerted area will determine the process of the osmosis condition the power generation is needed to maintain at the flux point where the hydro-turbine located. The condition for PRO is partially depending on the type of active layer of the semipermeable membrane where the layer allows to attract the solvent molecules to pass through membrane toward the concentrated solvent side by osmosis pressure. In this technique, one may use to generate power for both different salinity solvent separating by the layer of the membrane.

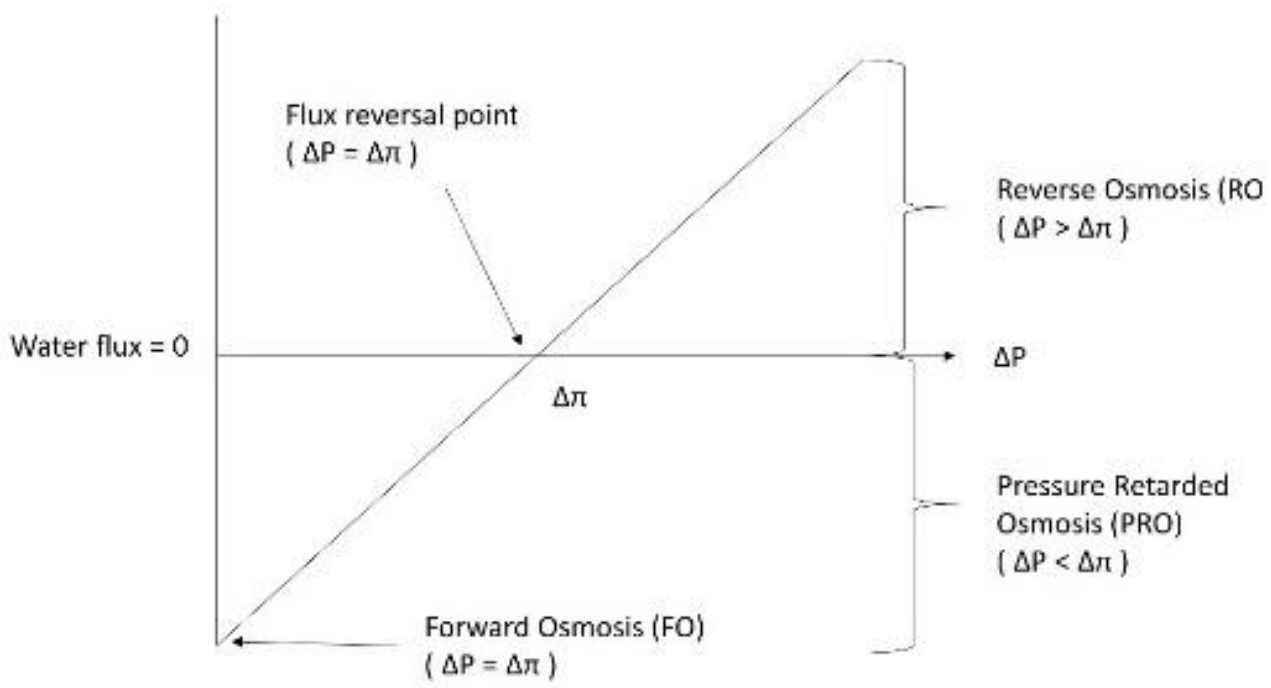

Fig. 2. Directory for the water flux exerted pressure in different condition for FO, PRO and RO.

a.
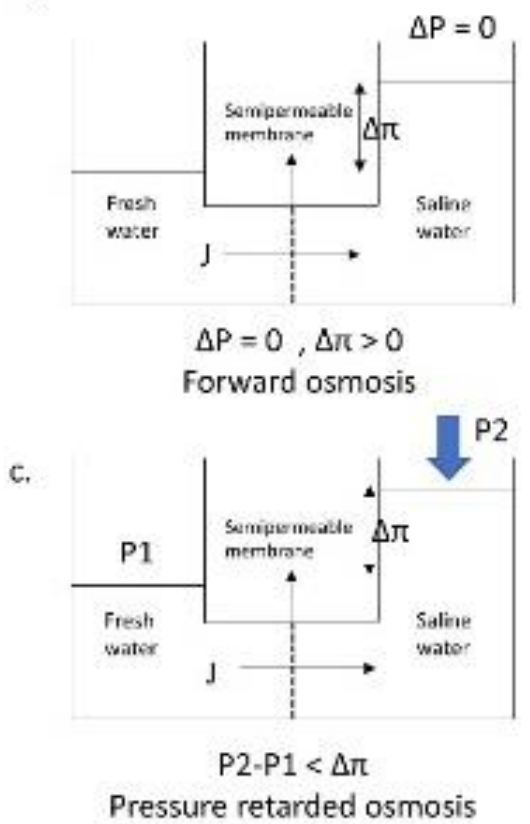

b.

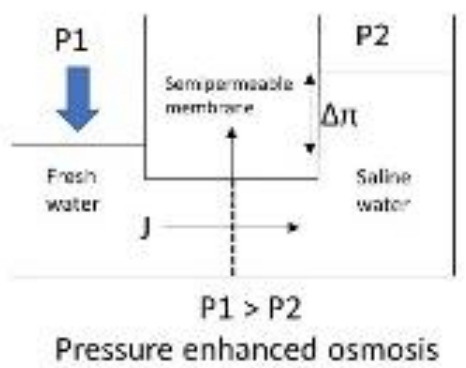

d.

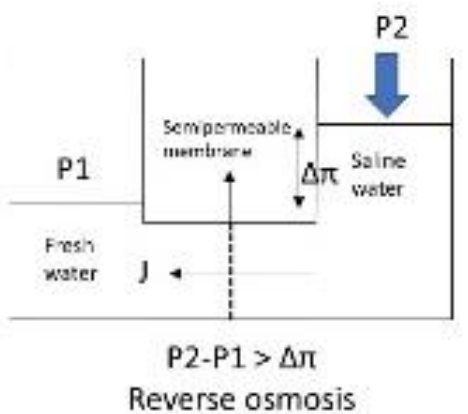

Fig. 3. Different condition of the osmosis in physical movement.

In Fig. 2, is shown the direction of water flux from the FO point located at the bottom of the axis, where pressure is applied in the feed side solution. PRO is where the pressure applied on the drawn side but flux in the direction as FO but the water flux is driven by the salinity different. In $\mathrm{RO}$, the water flow across the membrane with high salinity different to low salinity concentration, often this condition is for desalination of 
sea water purposes. The movement of forward osmosis FO taking place if hydrostatic pressure in $\Delta \mathrm{P}=0$, the flux will be operated by $\Delta \pi$ the osmotic differences. The condition of PRO function when the hydrostatic force from the feed chamber is less than the osmotic as in Fig. 1(b), the water flux still similar as the forward osmosis flux direction. Following the PRO condition if the $\Delta \mathrm{P}$ hydrostatic pressure larger than the osmotic pressure $\Delta \pi$, the condition of RO takes place where the water flux will carry from the high salinity solution to less salinity concentrated solution [6].

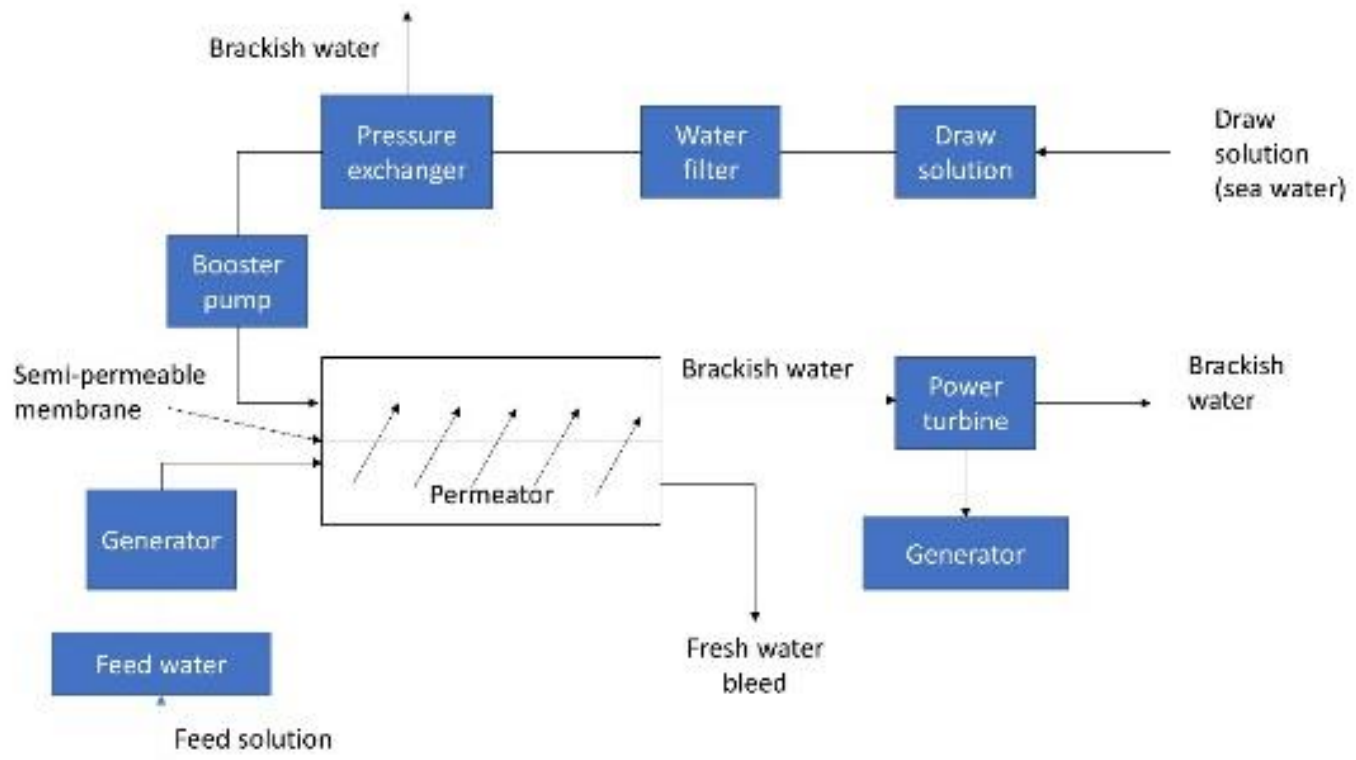

Fig. 4. Schematic diagram of power production from idealized PRO osmosis system.

\section{Osmotic Power Generation}

Osmotic pressure is the main mechanism for pressure retarded osmosis PRO system for power generation, in which it generated from different salinity gradient of the solution. Both solutions from sea and river which is separated by a semi-permeable membrane to create osmotic pressure for power generation. In pressure retarded system a water flow redirected into a module consisting of a semipermeable membrane that keeps the pressurized and saltier water flow separated [7]. Due to a higher osmotic pressure, the denser salt solution flow draws to the less concentrated solution through the semipermeable membrane, increasing the volume of the flow. In order to generate power, a hydroturbine is usually collecting the potential energy from the drawn solution overflow. The energy power from the hydro-turbine through PRO system is known as osmotic power.

In 1973, the PRO technology is introduced by Prof. Sidney Loeb regard the osmotic power generation concepts [7]. Over the years, the method has been developing until the Norwegian started the first osmotic prototype power plant by state-owned company Statkraft. The prototype plant was to study the semipermeable membrane to be cost-effective for large scale production in the future. The main issue for the membranes is easily caused blockage and the technology needed for an anti- fouling characteristic. During 2015, the plant has become the world's first prototype of the osmotic power generation plant.

According to [5], the current most intensively studied and well known of PRO technology by using river water and sea water for power generation. Based on the following arrangement in Fig. 1, the incoming feed solution from the river and drawn solution from the seawater are transferred into the semipermeable membrane chamber. Both solutions differential by semipermeable membrane with the active layer face toward sea water side, where the fresh water which is another side of the semipermeable membrane. The high concentration of the solution will attract the water molecules from fresh water toward sea water direction. This phenomenon helps the volume from the drawn solution side raises in volume and split the solution into two different pathways. The first path of the flow is to drive the hydro-turbine while the excess drawn of the solution may return to pressure exchange, where also the control feed of the inlet point. The pressure exchanger function to control the flow from the sea to the power plant. Furthermore, the feed solution can be sea water, just that it need pair with high salinity solution such as brine from water desalination plant [8] or hypersalinity solution from lake-salt and salt dome. 


\subsection{Osmotic Power with PRO}

The research on the alternative source to counter the world energy crisis, the idea of osmotic power generation is mentioned during 1950s by [9] and the proposed idea is rejuvenated during 1970s. The discussion idea during the 1970s is intensify as practical theory and experiment to justify the concept by Prof. Loeb [7]. The studied reported that the osmotic energy could be explored by the salinity differences. Nevertheless, the research decelerated in pace during the $80 \mathrm{~s}$ and $90 \mathrm{~s}$ due to the cost of the membrane is expensive, making the generation of osmotic power financially unviable. As the water treatment and desalination technology keep on rising which resulted in the advances of membrane technology, the cutting-edge research of the membrane was assisted the membrane cost reduce. Consequently, the research on the PRO technology was continually expanded in the 2000s [6,10].

In 2009, the Norwegian company establishes the first PRO prototype power plant. The PRO concept was proven can be used to generate electricity for large scale power supply to the local resident. Currently, the plant is innovating various kinds of membranes and a different configuration of the equipment to make osmotic power commercialized. The PRO osmotic power plant with the latest equipment arrangement as shown in Fig. 4. Generally, by using concentrated and high salinity solution, volume $\mathrm{V}$ with osmotic pressure $\pi_{D}$, such as sea water, to transfer into the plant known as hydraulic pressure of $P_{D}$. The product volume flow $(\mathrm{V})$ with the high salinity input of the hydraulic pressure $P_{D}$ produces the power input. Simultaneously, less concentrated water of feed solution, entering the membrane with low osmotic and hydraulic pressure. Based on Eq. (2) water molecules permeate from less concentrated to high concentration side with the rate $\Delta \mathrm{V}\left(\Delta \mathrm{V}=\mathrm{J} A_{m}\right.$, where $A_{m}$ denoting area of the membrane and $\mathrm{J}$ is the water flux which acquires a pressure of $P_{D}$ ).

By using the mixture of feed and drawn solution the new concentration of the salinity solution at drawn side achieved with low osmotic pressure value. The high salinity water side (volume $\mathrm{V}+\Delta \mathrm{V}$ ) as in Eq. (3) produces for the power with magnitude $P_{D}(\mathrm{~V}+\Delta \mathrm{V})$ when it enters a hydro-turbine the hydraulic pressure $P_{D}$ is reduced to zero value. Under the ideal PRO scheme, the maximum net power $\left(P W_{N E T}^{M A X}\right)$ that is generated where the power delivered by the hydro-turbine, $P_{D}$ $(\mathrm{V}+\Delta \mathrm{V})$, from the pressurized drawn water from the sea, $P_{D} \mathrm{~V}$ as shown in Eq. (3):

$$
P W_{\text {Net }}^{\text {Max }}=P_{D}(V+\Delta V)-P_{D} V=P_{D} \Delta V
$$

Equation (3) representing $\mathrm{V}$ as origin water volume and $\Delta \mathrm{V}$ as high salinity water volume difference after added from drawn side, $P_{D}$ hydraulic pressure from turbine, $\left(P W_{N E T}^{M A X}\right)$ net power overall generated.
Where $P_{D} \Delta \mathrm{V}$ is the net power system. The net power is at $100 \%$ efficiency for component with no energy lost. The feed solution is by assumption entering without any external force applied. The equation not for idea case where efficiency below 100\% for PRO system components which appear as a more logical condition, the net power would be shown as in Eq. (4):

$$
P W_{N e t}^{M a x}=P_{D} \Delta V_{\pi}
$$

Equation (4) is representing ( $\left.P W_{N E T}^{M A X}\right)$ net power generated, $V_{\pi}$ is representing the volume of the pumping water, and $P_{D}$ hydraulic pressure from turbine.

Where $\pi$ is representing the mechanical efficiency, it may be affected by the efficiency of the mechanical components such as pump, turbine, and generators, flow from the permeator and the equipment configuration in the plant [11]. For example, fresh water from river pairing with oceanic water can be produced about 1.0 MW of net power per $m^{3} s^{-1}$ estimating about $15 \%-20 \%$ from the theoretical net power achieved between both

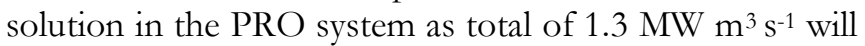

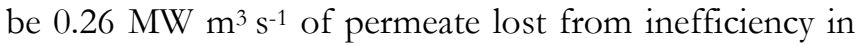
the osmotic power generation system components. According to [12], this indicates that efficiency for $40 \%$ compared to a total extractable energy mixing from feed and drawn water from the river and the sea respectively.

Therefore, PRO power generation plant will be depending on few criteria, which are crucial for the plant power output as equipment configuration, pressure drop, fictional pressure, efficiency and pressurized system [3]. The specific justification as below:

1) The arrangement and specific configuration of the equipment.

2) The frictional pressure drops across the high salinity membrane side.

3) Pressure lost across the membrane from fresh water, feed inlet.

4) The efficiency of the pump and mechanical equipment (hydro-turbine, fresh water pumping motor, seawater pumping motor and the purging motor)

5) Pressurized system and valve for the input of fresh water and sea water.

The net theoretical power $\left(P_{D} \Delta \mathrm{V}\right)$ is independent from the drawn solution based on Eq. (3). Instead, it depends on the operating pressure $\left(P_{D}\right)$ and water flux through the semipermeable membrane, $(J)$ which is a crucial parameter for choosing the membrane materials (A- permeability) create an osmotic pressure different as demonstrated in Eq. (2). This concludes that the operating pressure $\left(P_{D}\right)$ should be applied to the draw solutions in-order to generate high net powers. However, the incoming volumetric flow rate $(\mathrm{V})$ to which $P_{D}$ will indicate the inefficiency of the system in an actual PRO system. On the other hand, the low draw solution will 
trigger and increase in the membrane fouling tendency and a raise in power cost due reduce in hydraulic pressure. Similarly, a over draw of the solution will affect the system power output limit. In order to create an optimum power output osmotic power generation system, [7] stated that the volume of the draw solution cannot higher than the permeate in 2 -fold of the value $(\Delta \mathrm{V})$.

In the current time, the efficiency is assisted by the pressure exchanger as the drawn solution will be compressed [11] was the researcher to improve the PRO systems by pressure exchanger as reduce the pump motor workload by control the internal solution holding capacity. In the absence of the energy recovery system is cost higher than the pressurized system for the incoming water system (especially the draw solution). [6] mentioned that with the improved membranes, minimized energy losses and optimized flows, a float ground close to sea-level plant with pressure exchangers system can achieve an efficiency of $70 \%$.

\section{Filtration Membranes}

The performance of the membrane used in PRO often calculates the power output per membrane area or know as membrane power density [5]. The power density is crucial for the PRO system as it will affect the power generation capacity. The financial aspect for the plant operation and maintenance cost will be get covered as the power output per unit area of the membrane increases. Moreover, another factor for the osmotic power generation plant is the salt concentration or salinity gradient value which may a priority for the plant to operate at high efficiency. Although, the power density may limit the activity to a certain extent that makes it unprofitable as the costs of the power production increases. On the other hand, PRO membrane technology is to search for membrane material which could perform at least $5 \mathrm{M} \mathrm{m}^{-2}$ or higher to commercialize the osmotic power plant. According to Loeb et al. [11] emphasized that after a plant has been built, the power density is the determinant factor for the plant to be profitable. The main issue from the membrane is the fouling from the large particles in which it would cause blockage and affect the concentration polarization. Hence, the salinity gradient may reduce and reduce the power densities in PRO.

\section{Modelling for PRO}

The water flux modelling concept is used for $\mathrm{FO}$ and $\mathrm{RO}$, in early stage to measure the amount of freshwater crossing to the drawn side of the PRO osmosis system. One of the purposes for measuring the water flux of the fresh water is to calculate the power density which is to understand the mechanism to generate electricity in PRO. The fundamental model of water flux as shown in Eq. (2), subsequently the water flux developed by [13] as

$$
J_{w}=A\left[\pi_{D, b} \frac{1-\frac{C_{F, b}}{C_{D, b}} \exp J_{w} K}{1+\frac{B}{J_{w}}\left[\exp \left(J_{w} K\right)-1\right.}-\Delta P\right]
$$

Equation (5) representing $J_{w}$ as the water flux $\left(\mathrm{L} / \mathrm{m}^{2} / \mathrm{h}\right)$, $\mathrm{A}$ is the permeability coefficient of the membrane $\left(\mathrm{L} / \mathrm{m}^{2} / \mathrm{h} / \mathrm{bar}\right), \pi_{D, b}$ osmotic pressure from the drawn side (bar), $C_{F, b}$ is the water concentration from the feed side $(\mathrm{M}), C_{D, b}$ is the concentration from the drawn side $(\mathrm{M}), K$ is the solute resistivity (s/m), $\Delta P$ is the pressure gradient in (bar), B is solute permeability $\mathrm{m} / \mathrm{h}$.

Equation (5) have taken the consideration of the internal concentration polarization (ICP), however the equation is not provided the negative effect of the concentration polarization $\mathrm{CP}$ due to non-linearity. According to [14], have develop an equation included the impact of external concentration polarization (ECP) as (6).

$J_{w}=A\left[\pi_{D, b} \exp \left(-\frac{J_{w}}{k}\right) \frac{1-\frac{\pi_{F, b}}{\pi_{D, b}} \exp \left(J_{w} K\right) \exp \left(\frac{J_{w}}{k}\right)}{1+\frac{B}{J_{w}}\left[\exp \left(J_{w} K\right)-1\right]}-\Delta P\right]$

Equation (6) representing $J_{w}$ as the water flux $\left(\mathrm{L} / \mathrm{m}^{2} / \mathrm{h}\right)$, $\mathrm{A}$ is the permeability coefficient of the membrane $\left(\mathrm{L} / \mathrm{m}^{2} / \mathrm{h} / \mathrm{bar}\right), \pi_{D, b}$ osmotic pressure from the drawn side (bar), $\pi_{F, b}$ osmotic pressure from the feed side (bar), $C_{F, b}$ is the water concentration from the feed side (M), $C_{D, b}$ is the concentration from the drawn side $(\mathrm{M}), K$ is the solute resistivity $(\mathrm{s} / \mathrm{m}), \Delta P$ is the pressure gradient in (bar), B is solute permeability $\mathrm{m} / \mathrm{h}, \mathbf{k}$ is the bulk mass transfer coefficient $(\mathrm{m} / \mathrm{s})$

The concentrative of ECP on the feed side was not under consideration for Eq. (6), therefore for the final model is from [15], where taking consideration of the salt flux in the region of polarization near dilutive ECP.

$$
J_{w}=A\left[\frac{\pi_{D, b} \exp \left(-\frac{J_{w}}{K_{D}}\right)-\pi_{F, b} \exp \left(\frac{J_{w} S}{D}\right)}{1+\left(\frac{B}{J_{w}}\right)\left[\exp \left(\frac{J_{w} S}{D}\right)-\exp \left(-\frac{J_{w}}{K_{D}}\right)\right.}-\Delta P\right]
$$

Equation (7) representing $\mathrm{J}_{\mathrm{w}}$ as the water flux $\left(\mathrm{L} / \mathrm{m}^{2} / \mathrm{h}\right)$, $\mathrm{A}$ is the permeability coefficient of the membrane $\left(\mathrm{L} / \mathrm{m}^{2} / \mathrm{h} / \mathrm{bar}\right), \pi_{D, b}$ osmotic pressure from the drawn side (bar), $\pi_{F, b}$ osmotic pressure from the feed side (bar), $K$ is the solute resistivity (s/m), $\Delta P$ is the pressure gradient in (bar), B is solute permeability $\mathrm{m} / \mathrm{h}$, $\mathrm{D}$ drawn solution, $\mathrm{S}$ structure parameter.

According to Chae et al. [16], Equation (7) is considered for the mass balance and impact of the internal concentration polarization (ICP) and dilutive external concentration polarization (ECP). Every salt system is able to utilize this model equation for anticipate the flux value. 


$$
J_{w}=A\left\{\frac{\pi_{D, b}\left(\frac{r_{i}+\frac{D}{k_{D}}}{r_{i}}\right)^{-\frac{J_{w} r_{0}}{D}}-\pi_{F, b}\left(\frac{r_{0}}{r_{0}-\frac{D}{k_{F}}}\right)^{\frac{J_{w} r_{0}}{D}}\left(\frac{r_{0}}{r_{i}}\right)^{\frac{J_{w} r_{0} r}{D_{\varepsilon}}}}{1+\frac{B}{J_{w}}\left[\left(\frac{r_{i}}{r_{i}-\frac{D}{k_{F}}}\right)^{\left(\frac{J_{w} r_{0}}{D}\right)}\left(\frac{r_{0}}{r_{i}}\right)^{\frac{J_{w} r_{0} r}{D_{\varepsilon}}}-\left(\frac{r_{0}+\frac{D}{k_{D}}}{r_{0}}\right)^{-\frac{J_{w} r_{0}}{D}}-\Delta P\right\}}\right]
$$

Equation (8) representing $\mathrm{J}_{\mathrm{w}}$ as the water flux $\left(\mathrm{L} / \mathrm{m}^{2} / \mathrm{h}\right)$, A is the permeability coefficient of the membrane $\left(\mathrm{L} / \mathrm{m}^{2} / \mathrm{h} / \mathrm{bar}\right), \pi_{D, b}$ osmotic pressure from the drawn side (bar), $\pi_{F, b}$ osmotic pressure from the feed side (bar), $K$ is the solute resistivity (s/m), $\Delta P$ is the pressure gradient in (bar), B is solute permeability $\mathrm{m} / \mathrm{h}$, $\mathrm{D}$ drawn solution, $r_{0}$ outer radius from hollow fibre membrane, $r_{i}$ inner radius from hollow fibre membrane.

Equation (8) is designated for hollow fibre membrane, therefore with radius $\mathrm{r}$ in the equation representing the radius from the hollow fibre structure. This equation often is used for supporting layer of the membrane as porous layer membrane often refer as supporting layer [16].

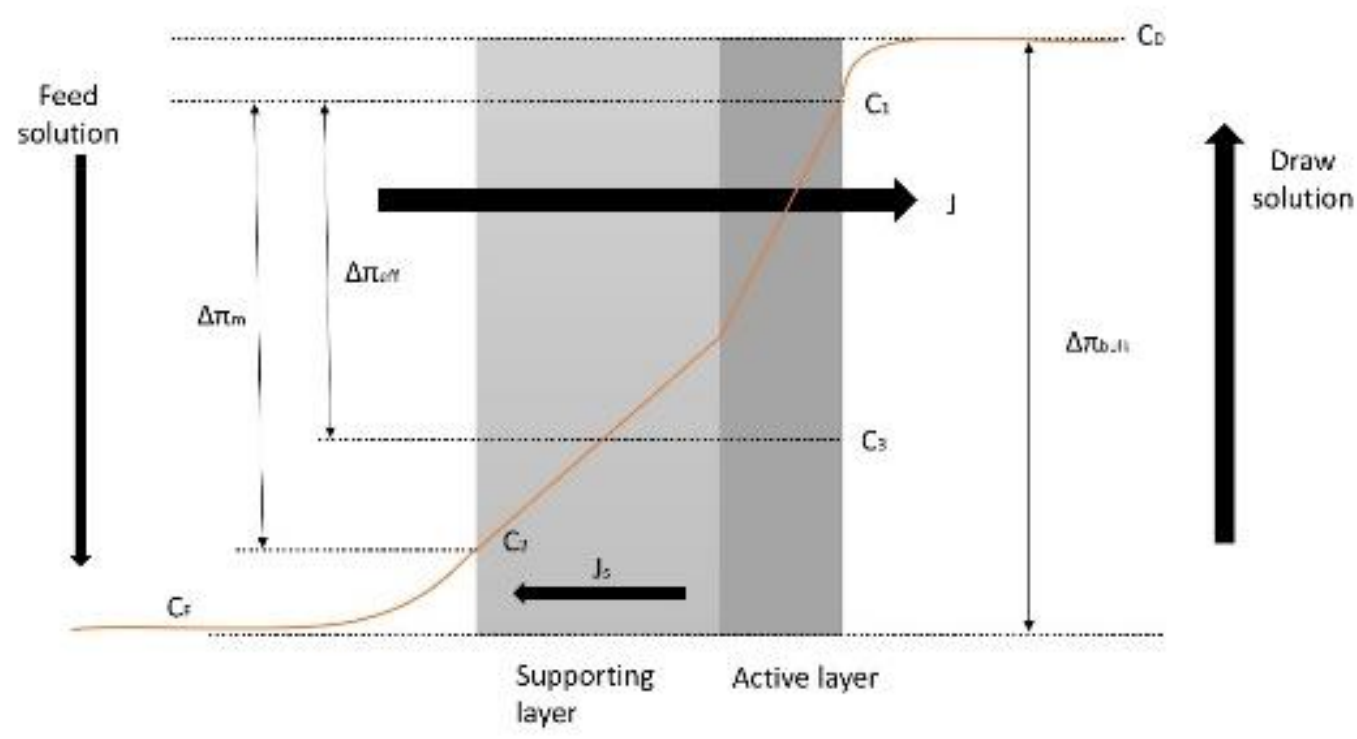

Fig. 5. The active layer and supporting layer of the membrane for PRO system water flux, various concentration $\mathrm{c}_{\mathrm{f}}, \mathrm{c}_{1}$, $\mathrm{c}_{2}, \mathrm{c}_{3}, \mathrm{c}_{\mathrm{d}}$, and osmotic pressure $\pi$.

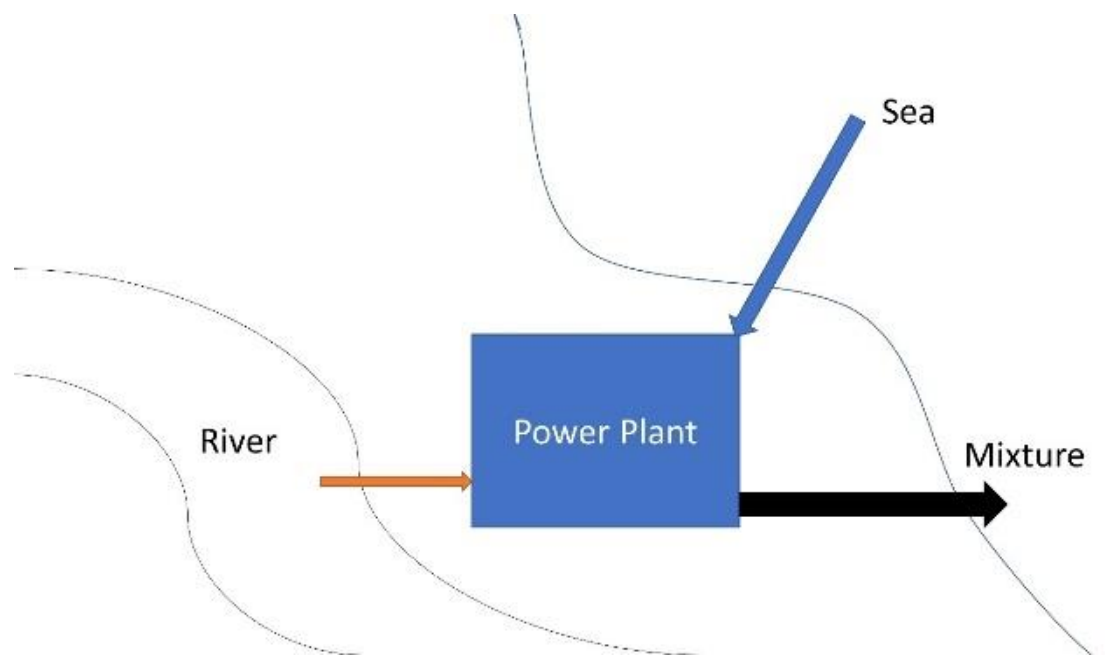

Fig. 6. The schematic diagram for a PRO power generation plant on water inlet and outlet information.

\subsection{Polarization Concentration}

Initial research for the osmotic power generation plant is mostly using RO membranes as the primary intercept for both different salinity solutions for PRO modules. The concentration polarization phenomena have introduced in 1970s which enrich the obstacles for the researcher to pursuit further on the osmotic power generation. An important aspect has raises, that is the membrane material properties which determine the efficiency and power density output for the system, where it also the obstacle as the financial cost of the 
membrane is expensive various materials have been put into consideration until the latest profound material, which meets the requirement as in Table 1 for the osmosis processes. Some material membrane that used to install in RO system may cause the efficiency for PRO to be very low due to the water permeability which further reduce the power density. The latest profound is the salinity polarization have placed the major factor for generating optimum water flux from the semipermeable membrane. According to [27] have been conducted an earlier laboratory experiment on PRO system which shown a very low value for power density a large gap from the theoretical calculation amount. After two consecutive hour the RO membrane that they used in the experiment has a sharp decline for the power output which cause by membrane fouling and limited water across the semipermeable membrane.

External concentration polarization (ECP) indicates the salt concentration on the external layer of the membrane $\left(C_{1}\right.$ and $C_{2}$ in Fig. 5). On the other hand, internal concentration polarization (ICP) was acknowledged the salt concentration of the membrane at the internal

layer of the membrane ( $C_{3}$ in Fig. 5). According to [17] mentioned if the salt concentration accumulation in the internal layer of the membrane would reduce the efficiency and the water flux across the membrane will be reduced, hence affect the power generation. This fact is indicating that the water flux is an important parameter for generating the osmotic pressure as $C_{1}$ and $C_{3}$ can be affecting the overall osmotic pressure.

As shown in Fig. 5, $J$ showing the water flux traveling across the supporting and active layer of the membrane. The concentration on the external layer of the membrane is equal to $C_{1}$ and becomes more diluted as the water traveled from the denser solution as the ROmembrane. In addition, the inverse flow of the flux from the denser solution side as ( $J_{S}$ in Fig. 5) to the feed solution side as the membranes are not perfectly semipermeable. Consequently, the different of the osmotic pressure or (the driving force of the water flux) is reduced due to the salt accumulation at the external layer of the membrane layers, thus decreasing the membrane power output. According to the recent studies by [15], the main cause for the flux to be declined in the PRO is the internal concentration polarization (ICP) causes dropped in power outputs of the membrane. External concentration polarization, in contradiction demonstrated have low affecting value due to the dropped in driving force to cause lower in the osmotic pressure. However, the phenomenon was proved to be essential under more water flux across the membrane to increase the power densities.

Table 1. PRO Simulation model and experimental operating condition.

\begin{tabular}{|c|c|c|c|c|}
\hline $\begin{array}{l}\text { Draw solution } \\
\text { concentration }(\mathrm{NaCl})\end{array}$ & Feed solution & $\begin{array}{l}\text { Optimum power } \\
\text { generation }\end{array}$ & Membrane types & Reference \\
\hline $\begin{array}{l}1 \mathrm{M} \mathrm{NaCl}(0 \text { pressure, } \\
20 \mathrm{C}, \mathrm{v}=0.25 \mathrm{~m} / \mathrm{s})\end{array}$ & $\begin{array}{l}\text { Deionised water }(8.62 \\
\text { bars, } 20 \mathrm{C}, \mathrm{v}=0.25 \\
\mathrm{~m} / \mathrm{s})\end{array}$ & $0.404\left(\mathrm{~kW} \mathrm{~h} / \mathrm{m}^{3}\right)$ & $\begin{array}{l}\text { Hydration Technology } \\
\text { Innovation, Thin layer } \\
\text { composite (HTI TFC) }\end{array}$ & [18] \\
\hline $\begin{array}{l}0.6 \mathrm{M} \mathrm{NaCl}(0 \text { pressure, } \\
25 \mathrm{C}))\end{array}$ & $\begin{array}{l}\text { Deionised water (3 } \\
\text { bar, } 25 \mathrm{C})\end{array}$ & $3.6\left(\mathrm{~W} / \mathrm{m}^{3}\right)$ & Thin layer composite & [19] \\
\hline $1.03 \mathrm{M} \mathrm{NaCl}$ & Deionised water & $5.06\left(\mathrm{~W} / \mathrm{m}^{3}\right)$ & Cellulose triacetate (CTA, FO) & [20] \\
\hline $1 \mathrm{M} \mathrm{NaCl}$ & $10 \mathrm{mM} \mathrm{NaCl}$ & $4.5\left(\mathrm{~W} / \mathrm{m}^{2}\right)$ & Cellulose triacetate (HTI, CTA) & [21] \\
\hline $2 \mathrm{M} \mathrm{NaCl}$ & $0.5 \mathrm{M} \mathrm{NaCl}$ & $4.7\left(\mathrm{~W} / \mathrm{m}^{2}\right)$ & Cellulose triacetate (HTI, CTA) & [22] \\
\hline
\end{tabular}

In PRO, the requirements of the membranes in comparison to the RO are notably different. For the case of $\mathrm{RO}$, since sea water forces its way from the membrane for the existing natural gradient osmotic pressure, the RO porous layer of the membrane needed to have dense, thick, and high hydrophobicity [23]. The concentration polarization is not a crucial factor for selecting a RO membrane compare to PRO membrane. This is because in $\mathrm{RO}$, higher selectivity of water molecules across the membrane module therefore the water is highly desalinated while it happens oppositely in PRO.

Loeb et al. [3] mentioned that the commercial RO membranes are less likely to be suitable for PRO as the membrane required to be thinner and able to obtain a higher water flux which could be permeated across to generate higher power density. Prior to this condition, FO membrane is similar to the criteria of the PRO membrane as it is much thinner as compared to RO 
membrane and higher permeate ability which suitable as prototype PRO membrane [24].

\section{Research and Progress of PRO Membrane}

The power density of the membrane has influenced the advances of the membrane technology with a combination of high-water molecules permeability, low salt molecules across the membrane and a higher salt permeability to the porous layer of the membrane. On top of that, PRO membrane should have excellent mechanical properties to within the water flux current flow across the membrane. In such, if compared with the RO system of the membrane, the PRO membrane has much thinner porous layer to reduce the internal salt accumulation [25]. The optimum membrane which is designed for maximized the power output balance between the two-membrane layer water permeability rate, which is the active and porous layer properties materials. However, the combination is limited to the supporting layer by parameter $S$ [15]. In the current market, thin films polyamide composite is conventionally used for $\mathrm{RO}$ membrane ranges from a typical $\mathrm{S}$ value refer to size of the membrane in diameter of $10,000 \mu \mathrm{m}$ which is denser amount to small value at $100 \mu \mathrm{m}$ [26], considering to be an encouraging news to the PRO membrane developers.

Table 2. Materials for active layer and supporting layer of the membrane.

\begin{tabular}{|l|l|l|l|}
\hline Synonym & Material & Properties & Reference \\
\hline CA & Cellulose acetate & $\begin{array}{l}\text { The main compound in the cellulose acetate is } \\
\text { acetylated cyclic hydroxyl. High acetylation will result in } \\
\text { higher hydrophobicity polymer, but it will cause } \\
\text { crystallinity when temperature raise. Reduce the } \\
\text { acetylation will increase the hydrophilic properties } \\
\text { which is favour for the osmosis driven, where } \\
\text { hydrophobic characteristic of the membrane would } \\
\text { enhance the membrane fouling rate. }\end{array}$ & \\
\hline PSf & Polysulfone & $\begin{array}{l}\text { The material has a good chemical resistance, } \\
\text { mechanical properties thermal oxidative resistance, } \\
\text { resistance to hydrolysis and industry solvent. A good } \\
\text { supporting layer for active layer membrane. It's regular } \\
\text { structure and not easily be crystalized }\end{array}$ & \\
\hline PBI & Polybenzimidazole & $\begin{array}{l}\text { The material able to process excellent physical } \\
\text { properties at higher temperature. It has good } \\
\text { mechanical and chemical resistivity. It is a potential } \\
\text { material for forward osmosis application. }\end{array}$ & \\
\hline PAI & Poly(amide-imide) & $\begin{array}{l}\text { The materials are compounding primary source with } \\
\text { polymers and have a good performance under extreme } \\
\text { conditions, against wear, creep and chemicals. It is also } \\
\text { use for nano-filtration system. }\end{array}$ & \\
\hline
\end{tabular}

The research for the membrane to enhance the parameter $\mathrm{A}$ is important to make the osmotic system to be high efficiency. The $\mathrm{B}$ and $\mathrm{S}$ value will determine the water flux permeability value to generate higher osmotic power. In this context, modelling studies have found that if the fabrication of the membrane according to the water permeability, thin, porous and resistant support layer is possible, then a peak power density at $9 \mathrm{Wm}^{-2}$ could attain by the combine of seawater and the fresh water into the PRO system [15]. Furthermore, [6] has emphasized if the PRO system has to be positive in the financial aspect the power density needs to locate around $5 \mathrm{Wm}^{-2}$ for high salinity and low salinity concentration different of water. Therefore, current restrict factor for membrane not available use as osmotic power generation because there have no specific company to produce for PRO system in power generation. Moreover, most of the laboratory experiment result is based on the FO and RO membrane to fabricate for the PRO power generation system. This is worth to denote that for commercialized the PRO system have to improve the technology in membrane fabrication to reduce the cost and viability in the market.

In the literature of [31], the author described that the limitation on the spiral wound module to solve the internal flow patter and pressure lost which is unfavourable for large scale purposes due to low power density production. The theoretical develop calculation of the membrane equipment estimated for million square meters from the membrane, it is infeasible as require large operating area. Additionally, it is also important that the design criteria should include criteria for avoiding membrane fouling which to increase the life span of the membrane. 


\section{The Environmental Impacts of Osmotic Power}

Osmotic pressure-based power generation with PRO in comparison with the current power production technologies was maintained a minimum of negative environmental impact compared to other power generation system [6]. Osmosis power plant has no gas emission as no combustion reaction occurrence, the water discharge from the plant is river water or mixed river with sea water solution. Furthermore, the plant location should be close to the coastal area only easy to reach for sea water to power-up the plant, where excess river water would only redirect to the plant for continuous the process. Even so, it should be noted that $\mathrm{PRO}$ is an underdeveloped technology which requires large scale operation in-order to thoroughly justify the real case scenario or conducting an environmental impact assessment. The model of the osmotic power plant from Statkraft, Norway river water that discharges to the ocean would have high salinity properties. Simultaneously, the sea water will be withdrawn from the sea a distant from the coastal area. During the power reduction process, the river water and sea water would be discharging the combine solution or known as blackish water to the mouth of the river where both sea and river water contacted area. In the process, environmental impacts may arise due to these deviations and discharge.

According to Walday et al. [32] and Staalstrøm et al. [33] mentioned about the potential impact of using river water and sea water as the feeding solution to the osmotic power plant. For the Statkraft, company plant, the sea water that is running is from deep sea water area around 25 meters the sea level from the ground. The deep-sea water nutrient value and consist of high microorganism within the water medium compare to the shallow zone of the sea water. The microorganism may cause blockage on the semipermeable membrane and affect the shallow region of the sea water quality by eutrophication. The effects of the eutrophication with the addition of phosphate are the challenge for a large scale of the osmotic power plant in the coastal area. According to [32], the water sample from the deep sea region about 35 meters of sea level onward consist of higher phosphate content compare to the shallow sea region. The euphotic layer of the organism at the shallow region of the sea water would affect the ecosystem of the area. The PRO power system may affect the regional sea water ecosystem in the long term of the plant operation which may need a proper environmental impact assessment.

The next challenge of the PRO system oversee is the temperature changes from the surface of the water affect by the combined water discharged. In this context refer to the temperature of the deep-sea water which is more stable compared to the shallow region of the sea water. The discharging water would have temperature different upon the different seasons of the shallow region of the sea water as an example summer would have colder water profile compare with the water discharge where winter season the water would be slightly higher. This temperature variation may affect the local aquatic organism and coral in the shallow region survivability. Next, the cleaning chemical used in the membranes has risen as a potential issue in the osmotic power production. The current cleaning solvent is similar to the RO membrane as the advances of RO membrane technology is much extensive in research [6]. Those cleaning agents have to be safe to the environment and not cause any toxicity to the environment as the priority. The concerning side was the potential side effect for the chemical agent which may harmful to the local environment as the membrane may require high tendency of cleaning rate if the water quality is not up to the standard. The pioneer osmotic power company statkraft have using the prototype plant conducted an environmental assessment on the local aquatic have reported there are no significant negative aspect found [32].

Apart from the nutrient content variation from the blackish water discharge, temperature variation, and the blackish water discharge from the power plant may consist of the salinity different which may contribute as one of the considerations factors which may affect the local aquatic plant. According to the Statkraft company the first prototype of the osmotic power plant in Norway, have been monitored for the salinity different effect which contributed from the blackish water salinity different to the shallow sea water salinity changes. However, the finding is depending on the location of the sea region and continental which have salinity changes. In the past research, [34] have shown that the discharge is diluted instead of raises the salinity rate, which bring a negative effect for the microorganism or $\mathrm{pH}$ sensitive organism.

\section{Market Value}

The economic analysis for the pressure retards osmosis (PRO) system where the structure construction fees, control system and membrane cost are the main sources. This technology is heavily depending on the strategic location of the plant to be constructed near to the coast area with fresh water stream source. Fresh water and sea water should be continuously supplied into the system therefore for low water of the river or inconsistence flow of fresh water will be affected by the power generation process. According to [35], the first prototype company for investing pressure retarded osmosis system PRO in power generation belongs to Statkraft company in Norway have anticipated to generate higher electrical power energy compared to hydropower energy by the reservoir. They have invested USD 12 million to develop the technique at Tofte, Norway. The plant has estimated to produce 1,600 TWh - 1,700 TWh, once commercialized. The current process cost is very expensive, the estimated power supply to 30,000 homes would require for 5 million square meters 
of membrane. The fouling issue has raised the cost as the researcher is still establishing inexpensive membrane technology for osmotic energy.

\section{Conclusion}

Pressure retard osmosis PRO power generation system is known as blue energy able to generate a vast quantity of electricity for power supplied. In this paper, have included the PRO osmosis fundamental working principle, latest pressure retard modelling equation, basic operating condition, membrane types and market value. The salinity different of $1 \mathrm{M} \mathrm{NaCl}$ would contribute for $0.404 \mathrm{~kW} \mathrm{~h} / \mathrm{m}^{3}$, where the cellulose acetylates CA and cellulose triacetate CTA as a common active layer of the membrane where polysulfone is used to be the supporting layer. The active layer is a high hydrophilic characteristic while supporting layer is high hydrophobic properties to create a concentration polarization region to control the flow. Pressure retard osmosis power generation system can be generating higher electricity compare to the hydropower system. Future trend of the PRO osmotic power generation system may resolve the high potential of fouling tendency from the membrane with anti-fouling material to expand the lifespan.

\section{Acknowledgement}

Financial support through the funding of YUTP grant (015LC0-169) from PETRONAS is acknowledged. The authors would also like to acknowledge Mdm. Norhayama Bt Ramli for technical advice.

\section{Appendix A}

\begin{tabular}{ll}
\hline Lists of Abbreviation \\
\hline $\mathbf{F O}$ & Forward osmosis \\
$\mathbf{R O}$ & Reverse osmosis \\
$\mathbf{P R O}$ & Pressure retard osmosis \\
$\mathbf{J}_{\mathbf{w}}$ & Water flux \\
$\mathbf{A}$ & Permeability coefficient \\
& of the membrane \\
$\boldsymbol{\pi}$ & Osmotic pressure \\
$\mathbf{C}$ & Concentration from the \\
& solution \\
$\mathbf{K}$ & Solute resistivity \\
$\mathbf{P}$ & Pressure gradient \\
$\mathbf{B}$ & Solute permeability \\
$\mathbf{k}$ & Bulk mass transfer \\
$\mathbf{S}$ & coefficient \\
$\mathbf{R}_{\mathbf{0}}$ & Structure parameter \\
$\mathbf{R}_{\mathbf{i}}$ & Outer Radius of fibre \\
& membrane \\
\hline & Inner radius of fibre \\
\hline
\end{tabular}

\section{References}

[1] Z. Zhou, et al., "A review of energy storage technologies for marine current energy systems," Renewable and Sustainable Energy Reviews, vol. 18, pp. 390-400, 2013.

[2] S. Loeb, F. V. Hessen, and D. Shahaf, "Production of energy from concentrated brines by pressureretarded osmosis II. Experimental results and projected energy costs," Journal of Membrane Science, vol. 1, no. 3, pp. 249-269, 1976.

[3] S. Loeb, "Production of energy from concentrated brines by pressure-retarded osmosis: I. Preliminary technical and economic correlations," Journal of Membrane Science, vol. 1, pp. 49-63, 1976.

[4] F. Dinger, T. Tröndle, and U. Platt, "Optimization of the energy output of osmotic power plants," Journal of Renewable Energy, vol. 2013, 2013.

[5] F. Helfer, C. Lemckert, and Y. G. Anissimov, "Osmotic power with pressure retarded osmosis: theory, performance and trends-A review," Journal of Membrane Science, vol. 453, pp. 337-358, 2014.

[6] S. E. Skilhagen, J. E. Dugstad, and R. J. Aaberg, "Osmotic power-Power production based on the osmotic pressure difference between waters with varying salt gradients," Desalination, vol. 220, no. 1-3, pp. 476-482, 2008.

[7] S. Loeb, et al., "The osmotic power plant," in 11th Intersociety Energy Conversion Engineering Conference, 1976.

[8] K. Saito, et al., "Power generation with salinity gradient by pressure retarded osmosis using concentrated brine from SWRO system and treated sewage as pure water," Desalination and Water Treatment, vol. 41, no. 1-3, pp. 114-121, 2012.

[9] R. Pattle, "Production of electric power by mixing fresh and salt water in the hydroelectric pile," Nature, vol. 174, no. 4431, p. 660, 1954.

[10] K. I. Peinemann, et al., "Membranes for power generation by pressure retarded osmosis," in Membranes for Energy Conversion. Wiley, 2007, ch. 9, pp. 263-273.

[11] S. Loeb, T. Honda, and M. Reali, "Comparative mechanical efficiency of several plant configurations using a pressure-retarded osmosis energy converter," Journal of Membrane Science, vol. 51, no. 3, pp. 323-335, 1990.

[12] N. Y. Yip and M. Elimelech, "Thermodynamic and energy efficiency analysis of power generation from natural salinity gradients by pressure retarded osmosis," Environmental Science \& Technology, vol. 46, no. 9, pp. 5230-5239, 2012.

[13] K. L. Lee, R. W. Baker, and H. K. Lonsdale, "Membranes for power generation by pressureretarded osmosis," Journal of Membrane Science, vol. 8, no. 2, pp. 141-171, 1981.

[14] A. Achilli and A. E. Childress, "Pressure retarded osmosis: From the vision of Sidney Loeb to the 
first prototype installation," Desalination, vol. 261, no. 3, pp. 205-211, 2010.

[15] N. Y. Yip, et al., "Thin-film composite pressure retarded osmosis membranes for sustainable power generation from salinity gradients," Environmental Science \& Technology, vol. 45, no. 10, pp. 4360-4369, 2011.

[16] S. H. Chae, et al., "Modeling and simulation studies analyzing the pressure-retarded osmosis (PRO) and PRO-hybridized processes," Energies, vol. 12, no. 2, p. 243, 2019.

[17] G. D. Mehta and S. Loeb, "Internal polarization in the porous substructure of a semipermeable membrane under pressure-retarded osmosis," Journal of Membrane Science, vol. 4, no. 2, pp. 261-265, 1978.

[18] Y. Chen, et al., "Optimization of module pressure retarded osmosis membrane for maximum energy extraction," Journal of Water Process Engineering, vol. 32, p. 100935, 2019.

[19] R. Long, et al., "Pressure retarded osmosis: Operating in a compromise between power density and energy efficiency," Energy, vol. 172, pp. 592-598, 2019.

[20] A. Achilli, T. Y. Cath, and A. E. Childress, "Power generation with pressure retarded osmosis: An experimental and theoretical investigation," Journal of Membrane Science, vol. 343, no. 1-2, pp. 42-52, 2009.

[21] Q. She, X. Jin, and C. Y. Tang, "Osmotic power production from salinity gradient resource by pressure retarded osmosis: Effects of operating conditions and reverse solute diffusion," Journal of Membrane Science, vol. 401, pp. 262-273, 2012.

[22] Y. C. Kim and M. Elimelech, "Potential of osmotic power generation by pressure retarded osmosis using seawater as feed solution: Analysis and experiments," Journal of Membrane Science, vol. 429, pp. 330-337, 2013.

[23] R. Baker, "Electrodialysis," in Membrane Technology and Applications. West Sussex, UK: Wiley \& Sons, Ltd, 2004, pp. 393-422.

[24] R. L. McGinnis, J. R. McCutcheon, and M. Elimelech, "A novel ammonia-carbon dioxide osmotic heat engine for power generation," Journal of Membrane Science, vol. 305, no. 1-2, pp. 13-19, 2007.
[25] T. Y. Cath, A. E. Childress, and M. Elimelech, "Forward osmosis: Principles, applications, and recent developments," Journal of Membrane Science, vol. 281, no. 1-2, pp. 70-87, 2006.

[26] N. Y. Yip and M. Elimelech, "Performance limiting effects in power generation from salinity gradients by pressure retarded osmosis," Environmental Science \& Technology, vol. 45, no. 23, pp. 10273-10282, 2011.

[27] C. E. Carraher, Jr., Carraher's Polymer Chemistry, 9th ed. CRC Press, 2013.

[28] F. Wehrmann, "Organic polymer chemistry, K. J. Saunders, Chapman and Hall, London, 1973, 473 pp.," Journal of Polymer Science: Polymer Letters Edition, vol. 13, no. 10, pp. 634-635, 1975.

[29] W. P. Zhu, et al., "Dual-layer polybenzimidazole/polyethersulfone (PBI/PES) nanofiltration (NF) hollow fiber membranes for heavy metals removal from wastewater," Journal of Membrane Science, vol. 456, no. 8, pp. 117-127, 2014.

[30] L. Setiawan, et al., "Fabrication of novel poly(amide-imide) forward osmosis hollow fiber membranes with a positively charged nanofiltrationlike selective layer," Journal of Membrane Science, vol. 369, no. 1-2, pp. 196-205, 2011.

[31] S. E. Skilhagen, "Osmotic power-A new, renewable energy source," Desalination and Water Treatment, vol. 15, no. 1-3, pp. 271-278, 2010.

[32] M. Walday, et al., "Monitoring of the outer Oslofjord 2010," Norwegian Institute of Water Research, Oslo, Norway, 2011.

[33] A. Staalstrøm and J. Gitmark, "Environmental impacts by running an osmotic power plant, Norwegian Institute for Water Research, Report SNO 6307-2012, 2012.

[34] Y. Fernández-Torquemada, J. L. Sánchez-Lizaso, and J. M. González-Correa, "Preliminary results of the monitoring of the brine discharge produced by the SWRO desalination plant of Alicante (SE Spain)," Desalination, vol. 182, no. 1-3, pp. 395-402, 2005.

[35] D. Clark, "Salt power: Norway project gives osmotic energy a shake," in National Geographic News. Oslo, Norway: National Geographic Society, 2013. 
Guo-Yong Yew, photograph and biography not available at the time of publication.

Zhen-Shen Liew, photograph and biography not available at the time of publication.

Soon-Onn Lai, photograph and biography not available at the time of publication.

Thiam-Leng Chew, photograph and biography not available at the time of publication.

Hee-Min Teh, photograph and biography not available at the time of publication.

Siti Habibah Shafiai, photograph and biography not available at the time of publication.

Man-Kee Lam, photograph and biography not available at the time of publication.

Jun-Wei Lim, photograph and biography not available at the time of publication.

Pau-Loke Show, photograph and biography not available at the time of publication.

Yeek-Chia Ho, photograph and biography not available at the time of publication. 